Article

\title{
The Influence of Gravity Waves on Ice Saturation in the Tropical Tropopause Layer over Darwin, Australia
}

\author{
Andrew M. Dzambo *, Matthew H. Hitchman $₫$ and Kai-Wei Chang $(\mathbb{D}$ \\ Department of Atmospheric \& Oceanic Sciences, University of Wisconsin-Madison, 1225 W. Dayton St., \\ Madison, WI 53706, USA; matt@aos.wisc.edu (M.H.H.); kchang37@wisc.edu (K.-W.C.) \\ * Correspondence: adzambo@wisc.edu
}

Received: 25 October 2019; Accepted: 27 November 2019; Published: 5 December 2019

check for updates

\begin{abstract}
Gravity waves (GWs) in the tropical tropopause layer (TTL) can help dehydrate the lower stratosphere through rapid cooling events, but observational studies of GWs in the TTL are limited. Using a long-term, high-resolution radiosonde temperature dataset, an atmospheric state classification technique, and wavelet analysis, we characterize temperature perturbations generated by GWs in the TTL over Darwin, Australia across eight atmospheric states. We find a peak in GW power just above the tropical tropopause and a climatological maximum during peak monsoon season. While accounting for a chronic negative temperature bias near the tropical tropopause, we estimate that, in the upper troposphere, GWs impose a $2 \mathrm{~K}$ temperature perturbation during non-monsoon states and a $3 \mathrm{~K}$ temperature perturbation during the monsoon states, with corresponding values of $5 \mathrm{~K}$ and $6 \mathrm{~K}$ in the upper TTL. A $3 \mathrm{~K}$ negative temperature perturbation will lead to significant perturbations in relative humidity with respect to ice, which has implications for environmental ice number concentrations and TTL cloud fraction.
\end{abstract}

Keywords: gravity waves; tropical tropopause; radiosondes; water vapor; ice saturation; clouds

\section{Introduction}

Understanding processes that lead to spatiotemporal changes in water vapor (WV) are critical for advancing our knowledge of the global climate system. In the upper troposphere and lower stratosphere (UTLS), where WV concentrations are almost always less than $10 \mathrm{ppmv}$, subtle changes in WV concentration can lead to changes in stratospheric ozone [1], other trace gas amounts [2], net heating, and vertical motion [3]. Air enters the stratosphere through the tropical tropopause layer (TTL). Over a long period of time, variations in WV concentration ultimately result in noticeable climate feedbacks [3], which have long-term effects on the planetary biosphere.

A number of processes affect the water vapor budget in the TTL. The vertical structure of the TTL plays a key role in the water vapor budget: unlike the mid-latitude tropopause, the TTL is rather deep, usually ranging from $\sim 14$ to $\sim 19 \mathrm{~km}$ [4]. Air masses traveling through the TTL frequently undergo dehydration, which result from long horizontal transport over approximately a few thousand $\mathrm{km}$. Over this horizontal distance, air masses slowly ascend, typically around a few hundred meters [5]. Cirrus and sub-visible cirrus clouds are frequently observed in the TTL because this long, slow vertical ascent increases ice supersaturation and subsequently enables efficient uptake/deposition of water vapor onto ice crystals [6]. Radiative cooling of TTL cirrus by deep convection can also aid in stratospheric dehydration [7]. Furthermore, buoyant updrafts and gravity waves generated by deep convection enable cirrus cloud growth, which dehydrates the stratosphere by as much as $0.3 \mathrm{ppmv}$ near the highest altitude in the TTL [8]. Clearly, a number of processes affect the TTL water vapor budget, however, quantifying the magnitude of dehydration through these processes remains challenging 
given the very low concentrations of water vapor in the TTL and uncertainties from existing in situ and remote sensing datasets.

The characteristics of gravity waves and their interactions in the TTL and middle atmosphere have been extensively studied [9-13]. Recent modeling and observational studies of the influence of gravity waves on ice crystal nucleation/growth/sedimentation and upper tropospheric cloud formation [12,14] highlight the connection between gravity waves and rapid cooling events, which often results in new ice formation $[15,16]$. The mean effective diameter of ice crystals in cirrus clouds decreases as temperatures decrease below $192 \mathrm{~K}$ [17]. Temperature fluctuations created by gravity waves at these temperatures can thereby influence the effective diameter of ice crystals, possibly creating a scenario where many small ice crystals rapidly form. Gravity waves generated by deep convection can transport and deposit ice crystals into the tropical lower stratosphere, where moistening can result from evaporating ice crystals [18,19]. The study by [20] examined cold-point temperature (CPT) changes instantiated by atmospheric waves. Their study, which included Kelvin, Rossby, mixed Rossby-gravity, and gravity waves, showed that wave activity acts to lower the cold-point temperature by $1.6 \mathrm{~K}$ with higher frequency waves contributing more cooling of the CPT. It is clear that, given the interplay between gravity waves and water vapor, observational datasets must adequately resolve a wide range of scales and sample a number of atmospheric regimes.

This study builds upon the analyses of [20] by exclusively characterizing gravity waves and their effect on ice saturation in the TTL using a long-term observational dataset and an atmospheric state classification technique. The classification technique, following Evans et al. (2012) [21], can improve previous results by clarifying the roles of convection and gravity waves in TTL water vapor modulation, instead of relying on traditional seasonal analyses (e.g., December-February versus June-August). The following questions are addressed to help achieve this goal:

1. When using an atmospheric state classification algorithm (as opposed to traditional seasonal analysis), how do the characteristics of gravity waves vary between convective (monsoon) and non-convective (non-monsoon) states?

2. Do gravity waves produce a measurable impact on ice saturation in the TTL?

\section{Experiments}

Gravity waves and water vapor are investigated using a variety of datasets and methodologies. All observational datasets are provided by the United States Department of Energy's Atmospheric Radiation Measurements (ARM) program's Darwin, Australia site (12 ${ }^{\circ} 29^{\prime} 5.6^{\prime \prime}$ S, $130^{\circ} 52^{\prime} 51.6^{\prime \prime}$ E; referred to as TWPC3) [22]. Unless otherwise noted, the datasets of choice span approximately 6.5 years from 18 January 2006 through 31 July 2012. The following subsections further describe the instrument datasets, the atmospheric state classification methodology (for segregating convective from non-convective states), and the wavelet analysis methodology (for estimating gravity waves and their characteristics from the radiosonde data).

\subsection{Radiosondes}

Vaisala RS92 radiosondes (Vantaa, Finland) are the primary data used in this study because they provide high-resolution ( $2 \mathrm{~s}$ ) sampling of wind, temperature, water vapor, and pressure, all of which are needed to characterize gravity waves and assess their impact on UTLS ice saturation. Radiosondes have a vertical ascent rate of approximately $5 \mathrm{~m} / \mathrm{s}$, providing a sampling interval of $\sim 10 \mathrm{~m}$, and typically ascend to altitudes between 20 and $30 \mathrm{~km}$ before bursting. These radiosondes are launched every six hours (i.e., four times a day) at the Darwin site over the 6.5-year period, thus providing an extensive dataset of the aforementioned variables. Wind speed and direction data are measured via a Global Positioning System (GPS) receiver and have uncertainties of $0.15 \mathrm{~m} / \mathrm{s}$ and $2^{\circ}$ azimuth, respectively. Temperature is measured using a capacitive wire, has a measurement uncertainty of $0.5 \mathrm{~K}$, and a resolution of $0.1 \mathrm{~K}$. The effect of gravity waves on ice saturation will be analyzed from temperature 
data only: radiosonde relative humidity data are not needed, therefore avoiding complications due to the known RS92 relative humidity (RH) dry-bias problem [23-25]. Radiosondes are ideal for this study because they take collocated measurements of wind and temperature, both of which are used as input into the wavelet analysis (see Section 2.3) such that gravity wave vertical wavelengths and amplitude (power), as well as potential and kinetic energy, can be measured [26]:

$$
\begin{aligned}
& K E=\frac{1}{2}\left(u^{2}+v^{2}\right) \\
& P E=\frac{1}{2} \frac{g^{2}}{N^{2}} \overline{\left(\frac{T^{\prime}}{T_{0}}\right)^{2}}
\end{aligned}
$$

where $u$ and $v$ are the zonal and meridional wind components respectively, $g$ is the acceleration due to gravity, $N$ is the Brunt-Väisälä frequency, $T^{\prime}$ is the perturbation temperature estimate and $T_{0}$ is the background mean temperature (i.e., a polynomial fit to the profile, see Section 2.3). While radiosonde measurements are excellent for measuring gravity waves in a Eulerian framework, these measurements do not resolve Lagrangian temperature fluctuations, which are also very important for contextualizing TTL dehydration [27].

\subsection{ARM Best-Estimate Cloud Radiation Product}

The ARM best-estimate cloud radiation product (ARMBECLDRAD) [28] is a value-added product provided by the ARM program to better facilitate climate studies. The ARMBECLDRAD product contains hourly data from several sources (such as millimeter cloud radars and microwave radiometers) and includes best-estimate measurements or retrievals of many variables including precipitable water vapor, surface temperature, cloud fraction, and incoming shortwave radiation. For this study, we employ the best-estimate outgoing longwave radiation and high altitude cloud fraction measurements to supplement our results using the radiosonde data.

\subsection{Wavelet Analysis}

Gravity waves are computed from radiosonde data using the methodology of Torrence \& Compo (1998) [29]. A wavelet analysis technique such as this one enables the decomposition of a series of data with uniform spatial or temporal spacing into time-frequency space. For this study, radiosonde zonal wind component and temperature data are utilized. Following previous studies [30,31], the perturbation zonal wind component and temperature are computed from the full zonal wind and temperature profiles, respectively, by assuming the background wind/temperature fields are represented by a polynomial fit. A fifth-order polynomial fit is chosen because, for this dataset, the ratio of the variance between the native radiosonde wind/temperature measurements and the reconstructed wind/temperature fields from the wavelet analysis is smallest (result not shown). The zonal wind and temperature perturbations are simply the difference between the full radiosonde measurement profile and the polynomial fit of each variable. To ensure that the wind and temperature fields in the lower and middle troposphere do not accidentally influence the polynomial fits, only data from $10 \mathrm{~km}$ to $25 \mathrm{~km}$ are considered. Finally, both temperature and zonal wind are interpolated such that the distance between each measurement is $5 \mathrm{~m}$. The "true" smallest resolvable vertical wavelength is actually $40 \mathrm{~m}$, given that the radiosonde sampling interval is $\sim 10 \mathrm{~m}$. The largest vertical wavelengths diagnosed using this technique are approximately $10 \mathrm{~km}$.

The wavelet analysis method has the added benefit of determining statistical significance in this data. For any input dataset, the time-frequency power spectrum is compared with a white-noise power spectrum. Any wave power exceeding this white-noise background is presumed to be statistically significant. Wave power is also normalized using this technique and, thus, allows wave power to be compared directly to other scales (vertical wavelengths) and radiosondes. Statistically significant wave power, as shown in Section 3, is binned according to atmospheric state in 2D altitude/wavelength space. 


\subsection{Atmospheric State Classification}

Radiosonde, gravity wave, and outgoing longwave radiation $(O L R)$ data are categorized according to the classification scheme of Evans et al. (2012) [21]. Evans [21] used a neural networking algorithm to categorize approximately four years of ECMWF reanalysis data [32] into eight distinct classifications-each with distinct dynamic, thermodynamic, and cloud properties. These classifications were developed using a $9 \times 9$ grid, with each grid box covering $2^{\circ} \times 2.5^{\circ}$. The classification results were not sensitive to horizontal resolution, selection of other input variables, or domain size [21]. An atmospheric state classification is assigned temporally, with each classification defining a 6-h window (up to four possible classifications possible over a 24-h period). Mean statistics of OLR, high cloud fraction, and gravity wave energy are computed as a function of each atmospheric state and are summarized in Table 1. For the purposes of this study, we wish to distinguish convective from non-convective states and, thus, place emphasis on the three rainiest states according to [21]: states 1 , 7 , and 8 .

Table 1. Mean outgoing longwave radiation $(O L R)$ and high cloud fraction based on ARMBECLDRAD data for the TWPC3 site, categorized by atmospheric state following [21]. Mean kinetic energy (KE), potential energy $(P E)$, total wave energy, and the ratio of $K E$ to $P E$ computed from TWPC3 radiosonde data using Equations (1) and (2) are also included. Only radiosonde data from $10 \mathrm{~km}$ to $25 \mathrm{~km}$ are considered in this computation.

\begin{tabular}{|c|c|c|c|c|c|c|}
\hline $\begin{array}{l}\text { Atmospheric } \\
\text { State }\end{array}$ & $\begin{array}{c}O L R \\
\left(\mathrm{~W} / \mathrm{m}^{2}\right)\end{array}$ & $\begin{array}{c}\text { High } \\
\text { Cloud Fraction (\%) }\end{array}$ & $\begin{array}{c}K E \\
(\mathrm{~J} / \mathrm{kg})\end{array}$ & $\begin{array}{c}P E \\
(\mathrm{~J} / \mathrm{kg})\end{array}$ & $\begin{array}{c}\text { Wave Energy } \\
(\mathrm{J} / \mathrm{kg})\end{array}$ & $\begin{array}{l}\text { Ratio of } \\
K E \text { to } P E\end{array}$ \\
\hline 1 & 285.4 & 41.3 & 10.3 & 10.9 & 21.2 & 0.94 \\
\hline 2 & 294.1 & 28.7 & 10.4 & 8.7 & 19.1 & 1.19 \\
\hline 3 & 307.3 & 23.3 & 9.6 & 8.2 & 17.9 & 1.17 \\
\hline 4 & 296.5 & 34.9 & 9.9 & 8.5 & 18.4 & 1.16 \\
\hline 5 & 289.8 & 44.8 & 9.7 & 10.4 & 20.1 & 0.93 \\
\hline 6 & 295.2 & 42.0 & 9.1 & 8.9 & 17.9 & 1.02 \\
\hline 7 & 271.6 & 88.3 & 11.5 & 15.0 & 26.5 & 0.77 \\
\hline 8 & 280.4 & 73.0 & 9.6 & 12.2 & 21.8 & 0.79 \\
\hline
\end{tabular}

Of the eight atmospheric states, state 7 has the most frequent convection and represents peak monsoon season during the months of January and February. In this state, high clouds are observed $88.3 \%$ of the time (on average) and correspond to the lowest $O L R\left(271.6 \mathrm{~W} \mathrm{~m}^{-2}\right)$ of any state (Table 1 ). Likewise, state 8 occurs most often near the beginning and end of the monsoon season and is the second cloudiest state based on OLR and high cloud fraction. State 1, despite occurring most often during the dry season, has the third lowest average $O L R$ of the eight states and has the largest high cloud fraction of the four dry-season states. Convection in this state, when it does occur, is often isolated and rarely peaks above $7 \mathrm{~km}$ according to [21]. High clouds in any of these states, generally speaking, are more likely to be advected horizontally rather than formed locally by convection. Overall, the statistics (especially $O L R$ ) presented in Table 1 qualitatively agree with Table 1 in [21]. Our computations of $K E$ and $P E$ (for the range of altitudes used) are similar to previous work [29]. Eddy potential energy is larger compared to eddy kinetic energy during both monsoon states, perhaps related to changes in static stability, which is a factor relating $\mathrm{T}^{\prime}$ and $\mathrm{u}^{\prime}$ in linear gravity wave theory.

Figure 1 shows an example of the wavelet analysis method applied to radiosonde data from state 7. Panels (A) and (B) reveal that the maximum power, using perturbation zonal wind as input, is associated with a peak vertical wavelength between 4 and $5 \mathrm{~km}$ and centered at approximately 18 to $19 \mathrm{~km}$ in altitude. Gravity waves with both small and large vertical wavelengths manifest themselves in the zonal wind and temperature profiles, and correspond to significant wave power from wavelengths as small as a few hundred meters to about $10 \mathrm{~km}$. In the results section, composite wavelength-altitude power spectra (as in Panel (B) of Figure 1) are constructed from all valid radiosonde data exhibiting statistically significant wave power in both zonal wind and temperature data. 
(A) Overall Power Spectrum

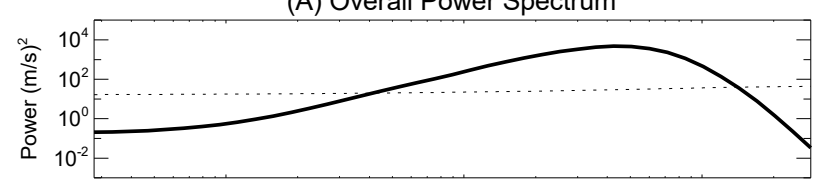

(B) Paul: Darwin - 20060201.111600, State: 7

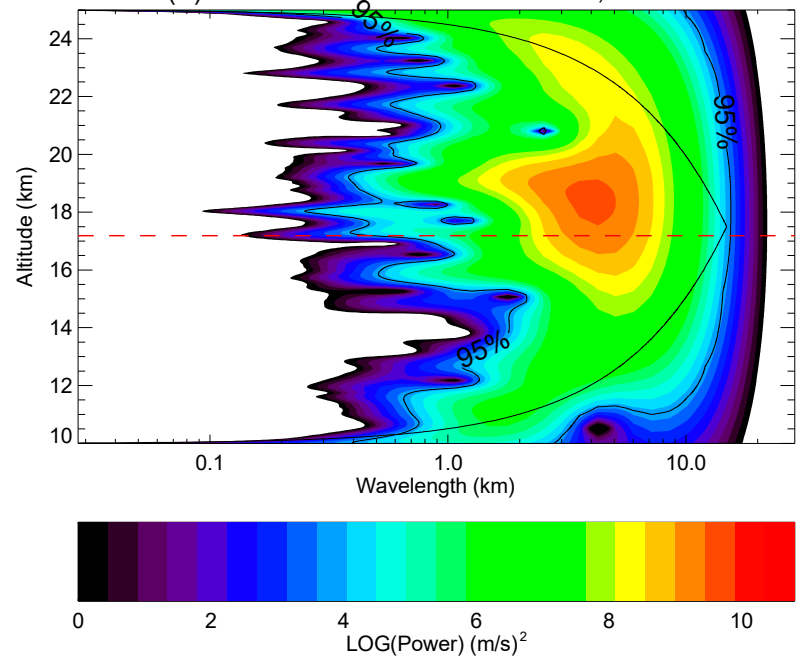

Peak Wavelength $=4.25 \mathrm{~km}$

Variance $=15.72(\mathrm{~m} / \mathrm{s})^{2}$

Recon. Variance $=15.22(\mathrm{~m} / \mathrm{s})^{2}$

Ratio $=1.03$

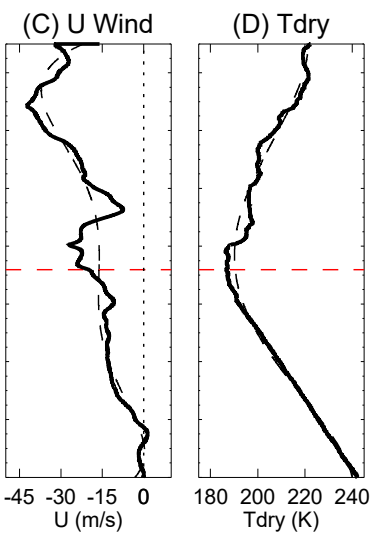

Figure 1. Wavelet analysis of a radiosonde launched on 1 February 2006 (State 7), where panel (A) represents the power spectrum at each wavelength bin, panel (B) is the time (altitude)/frequency (wavelength) decomposition of the perturbation zonal wind, panel $(\mathrm{C})$ is the zonal wind (U wind) component, and panel (D) is the dry-bulb temperature. The $95 \%$ confidence interval and "cone of influence", both following [29], are also shown on panel (B). The dashed line in panels (C) and (D) represent the background zonal wind and dry-bulb temperature (respectively), which is computed as a 5th order polynomial fit. The dashed red line represents the altitude of the tropopause, which is also computed from radiosonde temperature data.

\section{Results}

Figure 2 shows climatological altitude-wavelength wave power from gravity waves present in radiosonde data for all eight states prescribed according to [21]. Unsurprisingly, the climatological maximum in wave power occurs during the deep monsoon season of States 7 and 8 (Figure 2; Table 1). One interesting feature shown in these two figures is that the climatological maximum in gravity wave power, regardless of the peak vertical wavelength, occurs just above the tropopause, which is consistent with [30]. Previous studies using rocketsonde data revealed that gravity waves over deep convection tend to amplify into the stratosphere due to decreased density [33]. Data from the Middle Atmosphere Dynamics (MIDAS) campaign, which characterized gravity wave activity near the equator, revealed maxima in wave power above $35 \mathrm{~km}$ from approximately November through April, as well as a secondary maximum below $\sim 23 \mathrm{~km}$ during this same time [34]. Following our analysis and [34], the apparent amplification of gravity waves in the TTL from deep monsoonal convection has possible implications for TTL ice saturation. 

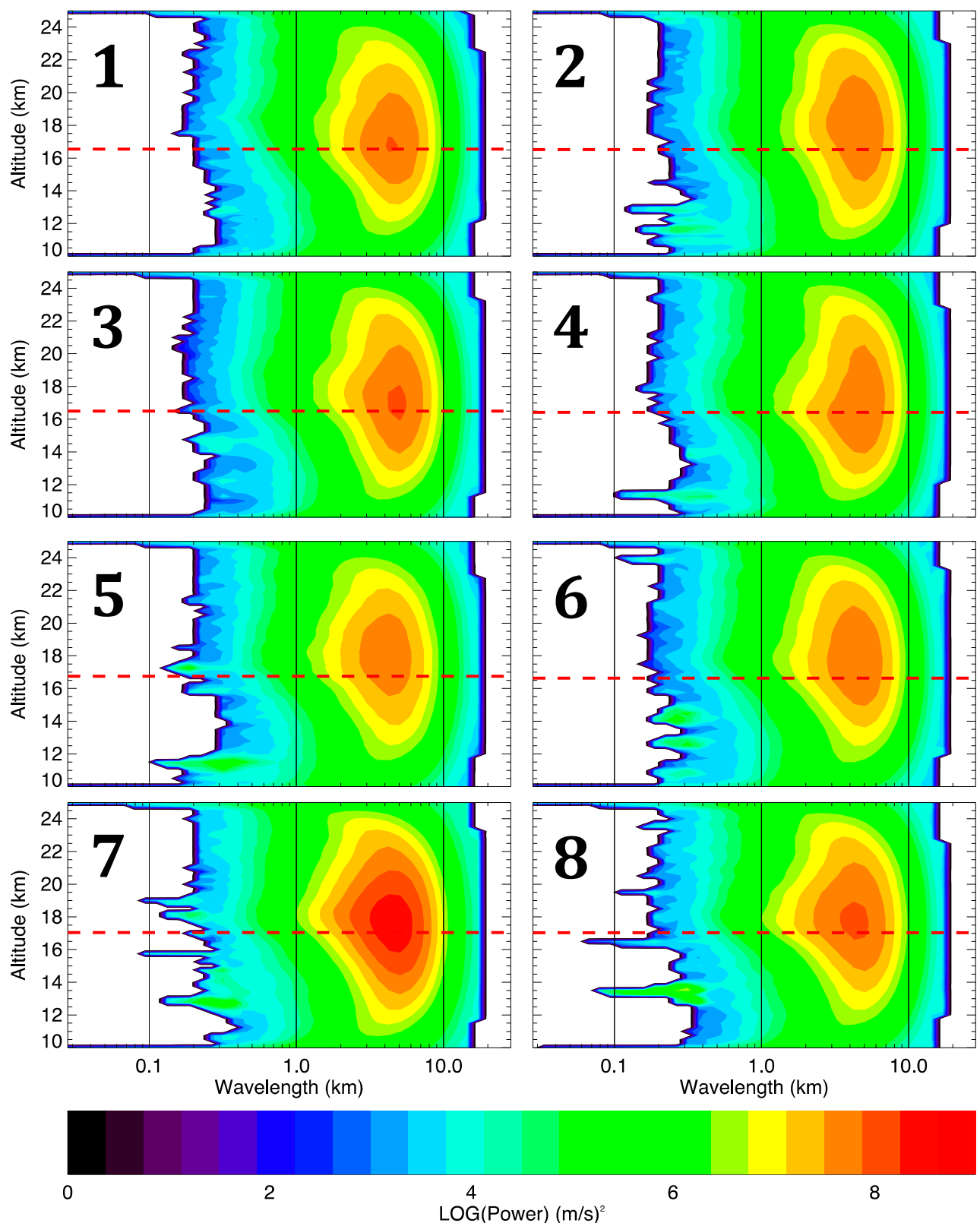

Figure 2. Time-frequency wave power spectrum using perturbation zonal wind for the eight atmospheric states, with each plot numbered according to atmospheric state. Only statistically significant wave power from individual radiosondes is used in each composite. The climatological tropopause altitude for each state is plotted as a dashed red line in each plot.

Deep convection in the tropics often reaches the tropopause and transports momentum and moisture into the TTL, which can then be advected quasi-horizontally. For strong convection, "overshooting tops" penetrating into the lower stratosphere generate gravity waves. We assume that perturbations against the background mean field are the result of these waves. Perturbations in temperature as a result of deep convection, therefore, can rapidly cool (or warm) the environment. In the case of deep convection, which in most cases is saturated from the lifting condensation level up through the level of neutral buoyancy, negative temperature perturbations instantiated by gravity waves will impose a sudden increase in ice supersaturation. If the environment is already colder than $-40^{\circ} \mathrm{C}$ ( $233 \mathrm{~K}$; required for homogeneous nucleation) or has ample cloud condensation nuclei, this increase in ice supersaturation can enable new nucleation of ice crystals and/or further ice crystal 
growth. Though we do not explicitly resolve either process in this study, our purpose for computing temperature perturbations from gravity waves is to provide further observational context for studies whose results, for example, predict increased ice number concentration [12,16], or show a decrease in effective diameter in very cold TTL temperatures [17] in the presence of gravity waves.

Climatological temperature perturbations for the four dry season states, two transition season states, and two monsoon season states, relative to the altitude of their respective tropopause, are shown in Figure 3. From 2.5 to $1.5 \mathrm{~km}$ below the tropopause, temperature perturbations caused by gravity waves are nearly uniform in all states. In general, from 2.5 to $0.5 \mathrm{~km}$ below the tropopause, the range is approximately $5 \mathrm{~K}$, with the subtle difference in range being less than the uncertainty in the radiosonde temperature measurements. Within $0.5 \mathrm{~km}$ of the tropopause, the range in gravity wave temperature perturbations is $10 \mathrm{~K}$ for monsoon states and $8 \mathrm{~K}$ for the dry season or transition season states. In the upper portion of the TTL, these values increase to $12 \mathrm{~K}$ and $10 \mathrm{~K}$, respectively.

One could argue that the reason the entire range of observed temperature perturbations near the tropopause are negative is due to the polynomial fit failing to capture the sharpness of the tropopause. In Figure 1, gravity waves are clearly present in both the temperature and wind profiles (panel (D)). The difference between the real temperature profile and the polynomial fit is negative near the tropopause, which is enhanced during monsoon states, with compensating slight warm biases above and below the tropopause. Here we emphasize the range of temperature perturbations (i.e., the width of the box and whisker plots in Figure 3). The range of temperature perturbations in the monsoon states is approximately $8.5 \mathrm{~K}$ near the tropopause and $12 \mathrm{~K}$ above it. The $1-3 \mathrm{~K}$ increase in range for monsoon states relative to the other states is almost surely due to higher amplitude gravity waves generated by deep convection. Overall, Figure 3 suggests that gravity wave temperature perturbations typically span $\pm 3 \mathrm{~K}$ and $\pm 2 \mathrm{~K}$ for the monsoon states and non-monsoon states (respectively) below the tropopause. Above the tropopause these results suggest larger perturbations at \pm 6 and $\pm 5 \mathrm{~K}$, respectively.

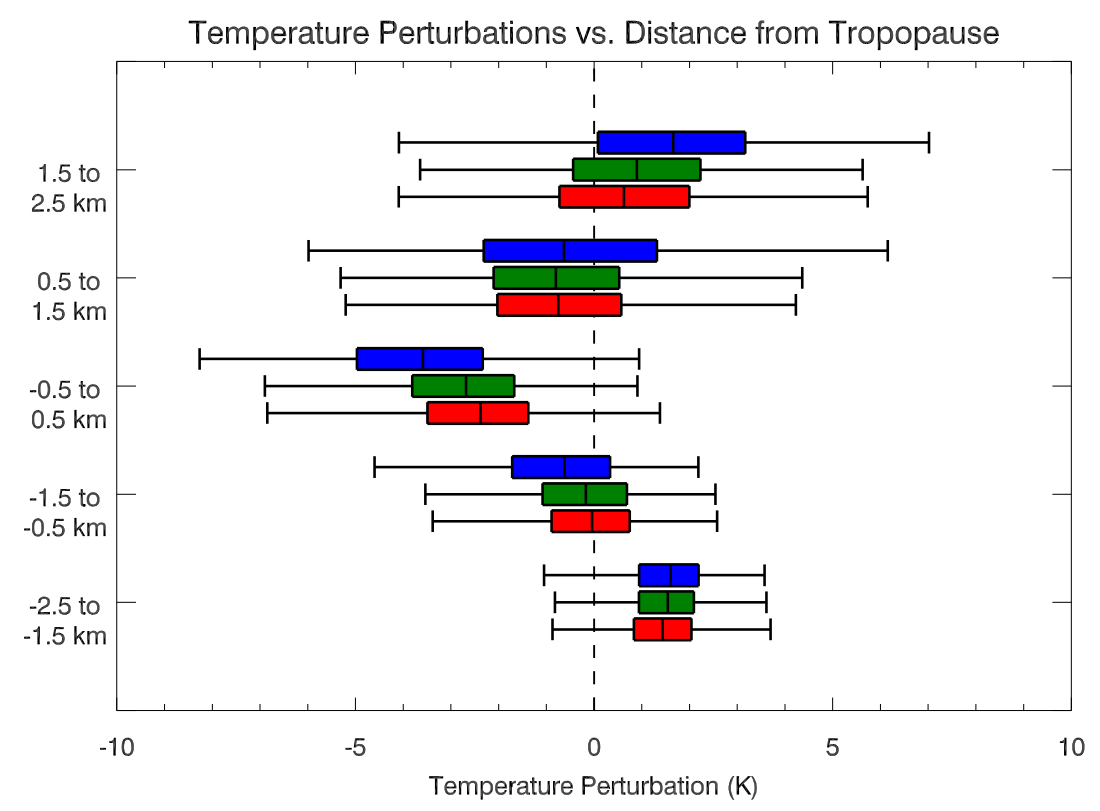

Figure 3. Box and whiskers plots (5th through 95th percentile) of temperature perturbations, relative to the height of the tropopause, for all dry season (states 1-4; red), transition season (states 5 and 6; green) and monsoon season (states 7 and 8; blue) data.

\section{Discussion}

The gravity wave generated negative temperature perturbations represent a pathway toward increased ice saturation in the TTL. Figure 4 shows lines of relative humidity with respect to ice (RHI) perturbations for typical TTL conditions. In a cold but dry atmosphere (temperature of 190 
or $200 \mathrm{~K}, \mathrm{RH}$ of $25 \%$ ) the RHI would increase by about $30 \%$ for a $-3 \mathrm{~K}$ temperature perturbation. For deep convection, where RH is large (65\% and $85 \%$ in Figure 4$)$, the same negative temperature perturbation would result, respectively, in RHI perturbations of about $75-130 \%$. For a gravity wave temperature perturbation of $-2 \mathrm{~K}$, which is characteristic of dry season or transition season states, the RHI perturbation is between $40 \%$ and $70 \%$ for an ambient temperature between $190 \mathrm{~K}$ and $200 \mathrm{~K}$. Despite the limitations of our dataset, including the typical maximum altitude of radiosondes, the temperature measurement uncertainty, and sharpness of the tropopause in computing gravity wave temperature perturbations, we feel confident that the temperature perturbations due to gravity waves are $\pm 2 \mathrm{~K}$ for non-monsoon states, and $\pm 3 \mathrm{~K}$ for monsoon states below the tropopause, increasing to values of $\pm 5 \mathrm{~K}$ and $\pm 6 \mathrm{~K}$ in the upper TTL. We also emphasize that, since our results are presented as climatological averages, gravity waves very close to the source of deep convection very likely have amplitudes exceeding $6 \mathrm{~K}$, thus implying a highly ice-saturated environment immediately surrounding deep convection. While our estimates provide additional observational context for high frequency gravity wave processes, accounting for Lagrangian effects on temperature fluctuations is also necessary for understanding dehydration [27] and cloud microphysical processes in the TTL [15-19]. Vertical velocity perturbations from gravity waves, which would also increase ice supersaturation, could be deduced from temperature perturbations across the entire gravity wave frequency spectrum [27] and will be the topic of future research.

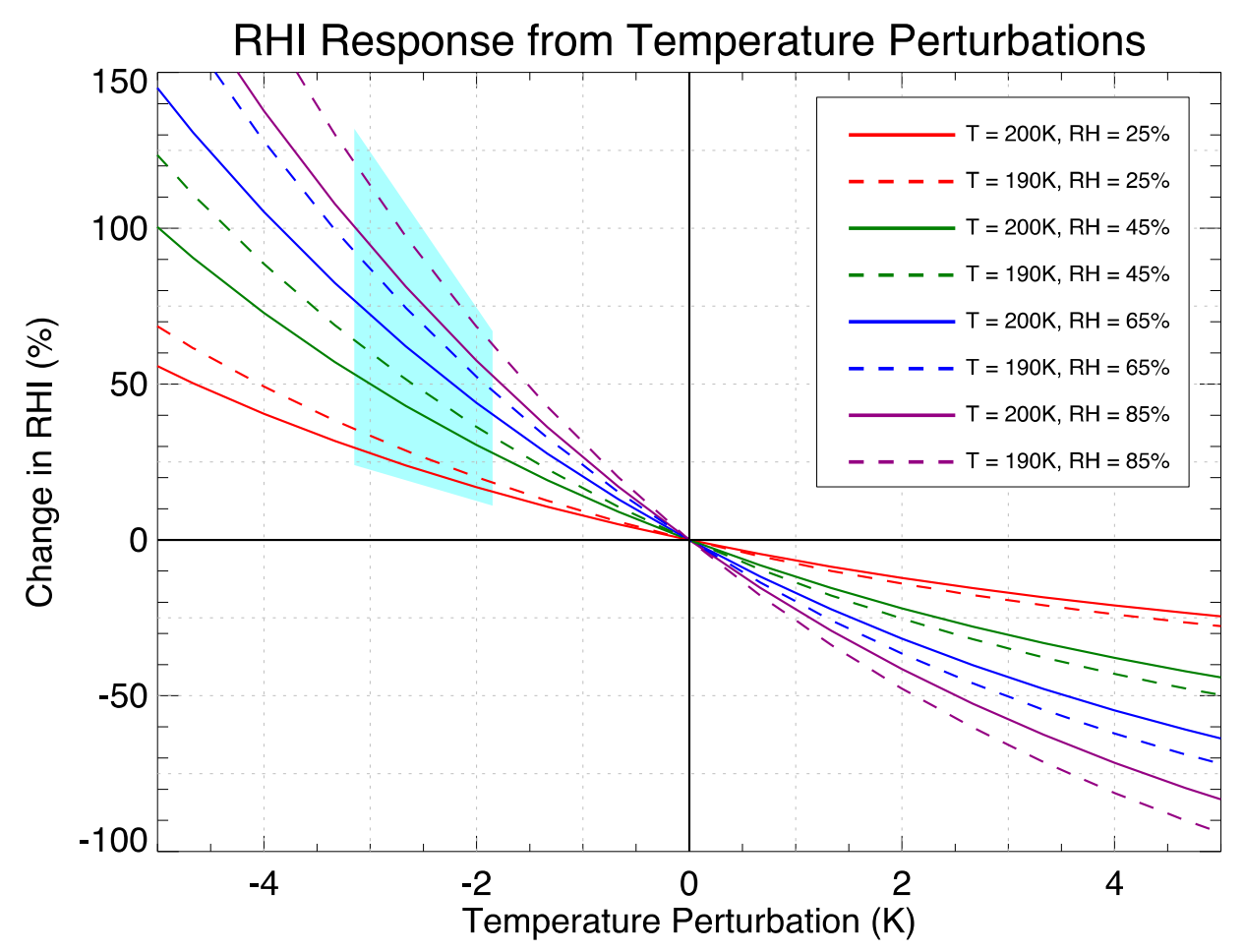

Figure 4. The change in relative humidity with respect to ice (RHI) as a result of temperature perturbations. Vapor pressure is first derived from the prescribed $\mathrm{RH}$ and saturation vapor pressure at the given temperature ( $200 \mathrm{~K}$ is solid, $190 \mathrm{~K}$ is dashed). Ice saturation vapor pressure is then computed for the given starting temperature and temperature perturbation (x-axis). Finally, RHI is re-computed using the original vapor pressure and ice saturation vapor pressure for the given temperature perturbation. The shaded light-blue region highlights changes in RHI from temperature perturbations between approximately $-2 \mathrm{~K}$ to $-3 \mathrm{~K}$. The difference in $\mathrm{RHI}$ as a result of the given temperature perturbation is shown on the $y$-axis. Water/ice saturation vapor pressure is computed according to [35]. 


\section{Conclusions}

Gravity waves in the TTL, as suggested by many previous studies, are responsible for rapid cooling events that, in the presence of enough water vapor, can lead to new ice nucleation, ice crystal growth, and/or increased TTL cloud fraction. These processes are especially likely during the monsoon season (state 7 in [21]), where gravity waves have the largest amplitudes (i.e., perturbations) and preside near a TTL cold point temperature that is typically less than $200 \mathrm{~K}$. Our results also note that the sharpness of the tropopause is not always caught by polynomial fitting and, to our knowledge, has not been addressed in previous studies using similar techniques. The $\pm 3 \mathrm{~K}$ temperature perturbation estimate for gravity wave perturbations during the monsoon season, and $\pm 2 \mathrm{~K}$ temperature perturbation estimate for all other states, exceeds the radiosonde temperature measurement uncertainty. Though we do not explicitly resolve a number of processes in this study (e.g., impacts on TTL cloud fraction, ice nucleation and ice crystal formation), our results provide further observational context for future studies examining cloud processes in the presence of gravity waves in the TTL. We suggest that future observational studies of TTL high frequency gravity waves focus on the variation at or near the center of deep convection as well as away from deep convection, where measurements in both regimes could further help describe TTL cloud and ice microphysical processes.

Author Contributions: Conceptualization: A.M.D. and M.H.H.; data curation: A.M.D.; formal analysis: A.M.D., M.H.H., and K.-W.C.; funding acquisition: K.-W.C.; investigation: A.M.D., M.H.H., and K.-W.C.; methodology: A.M.D.; project administration: M.H.H.; supervision: A.M.D. and M.H.H.; validation: A.M.D. and M.H.H.; visualization: A.M.D.; writing—original draft: A.M.D. and M.H.H.; writing—review and editing: A.M.D., M.H.H., and K.-W.C.

Funding: This study was supported by the NASA Earth and Space Sciences Fellowship 80NSSC17K0384.

Acknowledgments: The authors would like to thank the Atmospheric Radiation Measurements program for providing the radiosonde and cloud/radiation best estimate data used in this study. The authors would also like to thank Stuart Evans for providing the atmospheric state data for Darwin, Australia, Cameron Homeyer for insightful discussions on the subject of this paper, and Dave Turner for an independent, thoughtful review of this paper prior to its initial submission. Finally, the authors would like to thank three anonymous reviewers for their insightful comments and suggestions that improved the quality of this manuscript.

Conflicts of Interest: The authors declare no conflict of interest. The funders had no role in the design of the study; in the collection, analyses, or interpretation of data; in the writing of the manuscript; or in the decision to publish the results.

\section{References}

1. Chandra, S.; Ziemke, J.R.; Min, W.; Read, W.G. Effects of 1997-1998 El Nino on tropospheric ozone and water vapor. Geophys. Res. Letts. 1998, 25, 3867-3870. [CrossRef]

2. Ploeger, F.; Konopka, P.; Müller, R.; Fueglistaler, S.; Schmidt, T.; Manners, J.C.; Grooß, J.-U.; Günther, G.; Forster, P.M.; Riese, M. Horizontal transport affecting trace gas seasonality in the Tropical Tropopause Layer (TTL). J. Geophys. Res. 2012, 117, D09303. [CrossRef]

3. Solomon, S.; Rosenlof, K.H.; Portmann, R.W.; Daniel, J.S.; Davis, S.M.; Sanford, T.J.; Plattner, G.K. Contributions of stratospheric water vapor to decadal changes in the rate of global warming. Science 2010, 327, 1219-1223. [CrossRef] [PubMed]

4. Fueglistaler, S.; Dessler, A.E.; Dunkerton, T.J.; Folkins, I.; Fu, Q.; Mote, P.W. Tropical tropopause layer. Rev. Geophys. 2009, 47, RG1004. [CrossRef]

5. Holton, J.R.; Gettelman, A. Horizontal transport and the dehydration of the stratosphere. Geophys. Res. Letts. 2001, 28, 2799-2802. [CrossRef]

6. Jensen, E.J.; Toon, O.B.; Pfister, L.; Selkirk, H.B. Dehydration of the upper troposphere and lower stratosphere by subvisible cirrus clouds near the tropical tropopause. Geophys. Res. Letts. 1996, 23, 825-828. [CrossRef]

7. Hartmann, D.L.; Holton, J.R.; Fu, Q. The heat balance of the tropical tropopause, cirrus, and stratospheric dehydration. Geophys. Res. Letts. 2001, 28, 1969-1972. [CrossRef]

8. Potter, B.; Holton, J. The Role of Monsoon Convection in the Dehydration of the Lower Tropical Stratosphere. J. Atmos. Sci. 1995, 52, 1034-1050. [CrossRef] 
9. Vincent, R.A.; Allen, S.J.; Eckermann, S.D. Gravity-wave parameters in the lower stratosphere. In Gravity Wave Processes; Springer: Berlin/Heidelberg, Germany, 1997; pp. 7-25.

10. Fritts, D.C.; Alexander, M.J. Gravity wave dynamics and effects in the middle atmosphere. Rev. Geophys. 2003, 41, 1003. [CrossRef]

11. Fan, J.; Comstock, J.M.; Ovchinnikov, M.; McFarlane, S.A.; McFarquhar, G.; Allen, G. Tropical anvil characteristics and water vapor of the tropical tropopause layer: Impact of heterogeneous and homogeneous freezing parameterizations. J. Geophys. Res. 2010, 115, D12201. [CrossRef]

12. Dinh, T.; Podglajen, A.; Hertzog, A.; Legras, B.; Plougonven, R. Effect of gravity wave temperature fluctuations on homogeneous ice nucleation in the tropical tropopause layer. Atmos. Chem. Phys. 2016, 16, 35-46. [CrossRef]

13. Woods, S.; Lawson, R.P.; Jensen, E.; Bui, T.P.; Thornberry, T.; Rollins, A.; Pfister, L.; Avery, M. Microphysical properties of tropical tropopause layer cirrus. J. Geophys. Res. 2018, 123, 6053-6069. [CrossRef]

14. Schoeberl, M.; Dessler, A.; Ye, H.; Wang, T.; Avery, M.; Jensen, E. The impact of gravity waves and cloud nucleation threshold on stratospheric water and tropical tropospheric cloud fraction. Earth Space Sci. 2016, 3, 295-305. [CrossRef]

15. Schoeberl, M.R.; Jensen, E.J.; Woods, S. Gravity waves amplify upper tropospheric dehydration by clouds. Earth Space Sci. 2015, 2, 485-500. [CrossRef]

16. Jensen, E.J.; Ueyama, R.; Pfister, L.; Bui, T.V.; Alexander, M.J.; Podglajen, A.; Hertzog, A.; Woods, S.; Lawson, R.P.; Kim, J.-E.; et al. High-frequency gravity waves and homogeneous ice nucleation in tropical tropopause layer cirrus. Geophys. Res. Lett. 2016, 43, 6629-6635. [CrossRef]

17. Thornberry, T.D.; Rollins, A.W.; Avery, M.A.; Woods, S.; Lawson, R.P.; Bui, T.V.; Gao, R.-S. Ice water content-extinction relationships and effective diameter for TTL cirrus derived from in situ measurements during ATTREX 2014. J. Geophys. Res. Atmos. 2017, 122, 4494-4507. [CrossRef]

18. Kley, D.; Schmeltekopf, A.L.; Kelly, K.; Winkler, R.H.; Thompson, T.L.; McFarland, M. Transport of water through the tropical tropopause. Geophys. Res. Letts. 1982, 9, 617-620. [CrossRef]

19. Corti, T.; Luo, B.P.; De Reus, M.; Brunner, D.; Cairo, F.; Mahoney, M.J.; Martucci, G.; Matthey, R.; Mitev, V.D.; Santos, F.H.; et al. Unprecedented evidence for deep convection hydrating the tropical stratosphere. Geophys. Res. Letts. 2008, 35, L10810. [CrossRef]

20. Kim, J.-E.; Alexander, M.J. Direct impacts of waves on tropical cold point tropopause temperature. Geophys. Res. Letts. 2015, 42, 1584-1592. [CrossRef]

21. Evans, S.M.; Marchand, R.T.; Ackerman, T.P.; Beagley, N. Identification and analysis of atmospheric states and associated cloud properties for Darwin, Australia. J. Geophys. Res. 2012, 117, D06204. [CrossRef]

22. Turner, D.D.; Ellingson, R.G. The Atmospheric Radiation Measurement (ARM) Program: The First 20 Years; American Meteorological Society: Boston, MA, USA, 2017.

23. Miloshevich, L.M.; Vömel, H.; Whiteman, D.N.; Leblanc, T. Accuracy assessment and correction of Vaisala RS92 radiosonde water vapor measurements. J. Geophys. Res. 2009, 114, D11305. [CrossRef]

24. Wang, J.; Zhang, L.; Dai, A.; Immler, F.; Sommer, M.; Vömel, H. Radiation dry bias correction of Vaisala RS92 humidity data and its impacts on historical radiosonde data. J. Atmos. Ocean. Technol. 2013, 30, 197-214. [CrossRef]

25. Dzambo, A.M.; Turner, D.D.; Mlawer, E.J. Evaluation of two Vaisala RS92 radiosonde solar radiative dry bias correction algorithms. Atmos. Meas. Tech. 2016, 9, 1613-1626. [CrossRef]

26. Geller, M.A.; Gong, J. Gravity wave kinetic, potential, and vertical fluctuation energies as indicators of different frequency gravity waves. J. Geophys. Res. 2010, 115, D11111. [CrossRef]

27. Podglajen, A.; Hertzog, A.; Plougonven, R.; Legras, B. Lagrangian temperature and vertical velocity fluctuations due to gravity waves in the lower stratosphere. Geophys. Res. Lett. 2016, 43, 35433553. [CrossRef]

28. Atmospheric Radiation Measurement (ARM) User Facility. ARM Best Estimate Data Products (ARMBEATM); Xie, S., Chen, X., Eds.; Tropical Western Pacific (TWP) Central Facility: Darwin, Australia, 2008; updated hourly. [CrossRef]

29. Torrence, C.; Compo, G.P. A practical guide to wavelet analysis. Bull. Amer. Meteorol. Soc. 1998, 79, 61-78. [CrossRef]

30. Allen, S.J.; Vincent, R.A. Gravity wave activity in the lower atmosphere: Seasonal and latitudinal variations. J. Geophys. Res. 1995, 100, 1327-1350. [CrossRef] 
31. Moffat-Griffin, T.; Colwell, S.R. The characteristics of the lower stratospheric gravity wavefield above Halley $\left(75^{\circ} \mathrm{S}, 26^{\circ} \mathrm{W}\right)$, Antarctica, from radiosonde observations. J. Geophys. Res. 2017, 122, 8998-9010. [CrossRef]

32. Simmons, A.; Uppala, S.; Dee, D.; Kobayashi, S. ERA-Interim: New ECMWF reanalysis products from 1989 onwards. ECMWF Newsl. 2007, 110, 25-35.

33. Hamilton, K. Climatological statistics of stratospheric inertia-gravity waves deduced from historical rocketsonde wind and temperature data. J. Geophys. Res. 1991, 96, 20831-20839. [CrossRef]

34. John, S.R.; Kumar, K.K. TIMED/SABER observations of global gravity wave climatology and their interannual variability from stratosphere to mesosphere lower thermosphere. Clim. Dyn. 2012, 39, 1489-1505. Available online: https://doi-org.ezproxy.library.wisc.edu/10.1007/s00382-012-1329-9 (accessed on 21 November 2019). [CrossRef]

35. Murphy, D.M.; Koop, T. Review of the vapour pressures of ice and supercooled water for atmospheric applications. Quarterly Journal of the Royal Meteorological Society: A journal of the atmospheric sciences. Appl. Meteorol. Phys. Oceanogr. 2005, 131, 1539-1565.

(C) 2019 by the authors. Licensee MDPI, Basel, Switzerland. This article is an open access article distributed under the terms and conditions of the Creative Commons Attribution (CC BY) license (http://creativecommons.org/licenses/by/4.0/). 